\title{
Hypolipidemic effects of flavonoids extracted from Lomatogonium rotatum
}

\author{
LIDAO BAO $^{1}$, LIXIA HU ${ }^{2}$, YING ZHANG ${ }^{3}$ and YI WANG $^{1}$ \\ ${ }^{1}$ Department of Pharmacy, Affiliated Hospital of Inner Mongolia Medical University, Hohhot, Inner Mongolia 010059; \\ Departments of ${ }^{2}$ Hepatobiliary Surgery and ${ }^{3}$ Respiratory, Binzhou People's Hospital, \\ Binzhou, Shandong 256610, P.R. China
}

Received December 30,2014; Accepted September 15, 2015

DOI: $10.3892 / \mathrm{etm} .2016 .3038$

\begin{abstract}
Contained in the Mongolian volumes of Chinese Materia Medica, Lomatogonium rotatum Fries ex Nym. may reduce blood lipid levels and prevent obesity; however, its exact mechanism of action remains unclear. The present study investigated the hypolipidemic and obesity-inhibiting effects of four similarly structured flavonoids extracted from L. rotatum. According to a well-established method, flavonoids such as decussatin were extracted from the whole herb of L. rotatum, and male Wistar rats were subsequently fed a high-fructose diet supplemented with flavonoids $(20 \mathrm{mg} / \mathrm{kg}$ ) for 12 weeks. The levels of total cholesterol, triglyceride (TG), low-density lipoprotein-cholesterol and high-density lipoprotein-cholesterol (HDL-C) were detected. In addition, hepatic and epididymal adipose tissues were weighed, and levels of blood glucose, alanine aminotransferase, aspartate aminotransferase, non-esterified fatty acid, insulin and leptin were determined. The mRNA expression levels of fatty acid synthase (FAS) were analyzed using a reverse transcription polymerase chain reaction; whereas FAS, adenosine monophosphate-activated protein kinase (AMPK) and threonine-172 phosphorylated AMPK protein levels were detected by western blotting. The epididymal adipose tissues of rats fed with flavonoids were lighter, as compared with those fed with fructose in the model group. Following a 12-week administration of flavonoids, the serum levels of fasting blood glucose, feeding blood glucose and leptin were decreased. Furthermore, flavonoid treatment reduced TG and cholesterol levels in the blood and increased serum HDL-C levels, as compared with the model group. High-fructose diet administration significantly increased FAS mRNA and protein expression levels, whereas the FAS protein levels of flavonoid-treated rats were markedly reduced.
\end{abstract}

Correspondence to: Professor Yi Wang, Department of Pharmacy, Affiliated Hospital of Inner Mongolia Medical University, 1 Tongdao Avenue North, Hohhot, Inner Mongolia 010059, P.R. China E-mail: wang_yi237@163.com

Key words: Mongolian medicine, Lomatogonium rotatum, flavonoid, hyperlipidemia, rat
The flavonoid compounds also enhanced threonine-172 phosphorylation of AMPK in the liver lysate, and all flavonoids successfully downregulated leptin levels and the majority decreased the relative weights of epididymal adipose tissue. Therefore, flavonoids may function in a similar way to epigallocatechin gallate, which has previously been shown to inhibit FAS activity by stimulating AMPK in hepatocyte cells via the liver kinase B1 pathway.

\section{Introduction}

Lomatogonium rotatum Fries ex Nym., which is referred to as 'Habirigan-Digeda' in Mongolian, is the whole plant of a Gentian family herb with a height of $15-40 \mathrm{~cm}$. L. rotatum is contained within the Mongolian volumes of Chinese Materia Medica. As an annual herb growing on hillsides, grasslands and near ditches, L. rotatum is preferentially distributed in the mountain areas of Inner Mongolia in China. L. rotatum contains flavonoids including cynaroside and orientin (1), which previous studies have shown to be useful in the treatment of dyspepsia, gall bladder swelling, jaundice and inflammation of the liver and gallbladder (2,3). Previous studies evaluating long-term treatment with $L$. rotatum have demonstrated that it may lower blood lipid levels and prevent obesity $(1,4)$; however its exact mechanism of action remains to be fully elucidated. Daily foodstuff contains some natural fructose and in recent years foods with considerable refined fructose content have become fairly popular. This is a worrying trend as a high intake of foods rich in fructose is associated with obesity and metabolic problems (5).

The lipogenic capacity exhibited by liver and adipose tissue is controlled by fatty acid synthase (FAS), and it has previously been demonstrated that FAS gene expression is vital for the conversion of fructose into lipids (6). At present, individuals often suffer from hyperlipidemia due to changes in the metabolism of lipids, and hyperlipidemia contributes to arteriosclerosis and coronary heart disease (CHD). In addition, it has been reported that high levels of triglyceride (TG) may increase the risk of CHD (7).

Previous studies have determined the effects of flavonoids extracted from $L$. rotatum, particularly decussatin, which has been shown to inhibit the growth of HEP-G2 hepatoma cells, resulting in reduced blood glucose levels and a decrease in 
depression, leukemia and tuberculosis $(8,9)$. However, studies regarding the hypolipidemic effects of the following flavonoids: 1-hydroxy-3,5,8-trimethoxyxanthone, methyl swertiamarin and 6,8-dihydroxy-1,2-dimethoxyxanthone are rare (10-12).

Previous studies have demonstrated that $L$. rotatum is able to decrease blood glucose; therefore, L. rotatum may potentially be useful as a prophylactic treatment for atherosclerosis (13). In addition, following the long-term consumption of high-fructose foods, adenosine monophosphate-activated protein kinase (AMPK) in L. rotatum may continuously suppress hyperlipidemia, hyperleptinemia and FAS (14). Therefore, in the present study the hypolipidemic and obesity-inhibiting effects of four flavonoids isolated from L. rotatum (Fig. 1) were investigated in Wistar rats.

\section{Materials and methods}

Materials. Enzyme assay total cholesterol (TC; \#4220), triglyceride (TG; \#4240), polyethylene sulfate precipitation method low-density lipoprotein-cholesterol (LDL-C; \#4210) and phosphotungstic acid-magnesium precipitation method high-density lipoprotein-cholesterol (HDL-C; \#4200) kits were purchased from Biosino Bio-Technology and Science, Inc. (Beijing, China). Flavonoids A-D were yellow needle-like crystals with the following molecular weights: A, $302 \mathrm{~g} / \mathrm{mol}$; $\mathrm{B}, 302 \mathrm{~g} / \mathrm{mol}$; C, $288 \mathrm{~g} / \mathrm{mol}$ and D, $288 \mathrm{~g} / \mathrm{mol}$. The four flavonoids were extracted and synthesized at the Inner Mongolia Medical University (Hohhot, China) (15), and uniformly mixed into the basic feeds of the experimental rats. Anti-FAS (MHCD9528) was purchased from Thermo Fisher Scientific, Inc. (Carlsbad, CA, USA), and anti-phospho AMPK (AA393), anti-AMPK (AA393-1; Beyotime Institute of Biotechnology, Shanghai, China), and horseradish peroxidase-conjugated anti-mouse (NCAM-1/CD56; R\&D Systems, Inc., Minneapolis, MN, USA) and anti-rabbit (ab191866) antibodies were purchased from Abcam (Cambridge, UK).

Animals and treatment. The present study complied with all protocols and policies outlined by the Animal Care and Use Committee of Inner Mongolia Medical University. The present study complied with all protocols and policies outlined by the Animal Care and Use Committee of Inner Mongolia Medical University (Huhhot, China). A total of 60 six-week-old male Wistar rats (weight, 150-200 g), were provided by the Experimental Animal Center of Inner Mongolia Medical University, and were housed at the Inner Mongolia Medical University in stainless steel wire-bottomed cages. The rats were acclimated to the laboratory conditions $\left(19-23^{\circ} \mathrm{C}\right.$, $60 \%$ humidity and 12-h light/dark cycle) for at least 1 week prior to the initiation of the present study, during which the rats received ad libitum access to water and Purina ${ }^{\circledR}$ rat food. Following one week of acclimation, the rats were divided into the following groups, and subsequently weighed every week for 12 weeks (16-18): Control group, basic diet (Purina ${ }^{\circledR}$ rat food); Model group, high-fructose diet (40\% Purina ${ }^{\circledR}$ rat food $+60 \%$ fructose); Group A, high-fructose diet $+20 \mathrm{mg} / \mathrm{kg}$ flavonoid A; Group B, high-fructose diet $+20 \mathrm{mg} / \mathrm{kg}$ flavonoid B; Group C, high-fructose diet $+20 \mathrm{mg} / \mathrm{kg}$ flavonoid C; Group D, high-fructose diet $+20 \mathrm{mg} / \mathrm{kg}$ flavonoid D. Blood samples were collected from the femoral arteries of the rats, and the serum was separated in order to detect the levels of TC, TG, HDL-C and LDL-C. Hepatic, kidney and epididymal adipose tissue samples were harvested, weighed and stored at $-70^{\circ} \mathrm{C}$.

Determination of TG. Serum levels of TG were analyzed using the glycerol-3-phosphate oxidase/phenol and aminophenazone method (Biosino Bio-Technology and Science Inc.) $(19,20)$. TG was enzymatically hydrolyzed to glycerol and free fatty acids using specific lipases, which were subsequently oxidized into $\mathrm{H}_{2} \mathrm{O}_{2}$ using glycerol kinase and glycerol phosphatase. $\mathrm{H}_{2} \mathrm{O}_{2}$ was then converted into colored quinonimine via a peroxidase-catalyzed reaction with 4-aminoantipyrine and phenol. The levels of TG in the serum samples were determined at $520 \mathrm{~nm}$ and expressed as $\mathrm{mg} / 100 \mathrm{ml}(21)$.

Determination of TC. Serum levels of TC were measured using the cholesterol oxidase/phenol and aminophenazone (CHOD-PAP) method (Biosino Bio-Technology and Science Inc.). Using detergents, cholesterol and its esters were released from lipoproteins prior to hydrolyzation of the esters using cholesterol esterase, which were subsequently enzymatically oxidized into $\mathrm{H}_{2} \mathrm{O}_{2} \cdot \mathrm{H}_{2} \mathrm{O}_{2}$ was then converted into colored quinonimine via a peroxidase-catalyzed reaction with 4-aminoantipyrine and phenol. The levels of TC in the serum samples were determined at $520 \mathrm{~nm}$ and expressed as $\mathrm{mg} / 100 \mathrm{ml}(21)$.

Determination of HDL-C. LDL was precipitated by phosphotungstic acid and magnesium ions, which were subsequently removed by centrifugation in order to suspend the HDL in the supernatant. HDL-C was then measured using the CHOD-PAP method (Biosino Bio-Technology And Science Inc.). The levels of HDL-C in the serum samples were expressed as $\mathrm{mg} / 100 \mathrm{ml}$.

Determination of $L D L-C$. LDL was precipitated by heparin at its isoelectric point ( $\mathrm{pH}$ 5.12). HDL remained in the supernatant following centrifugation and the levels of LDL-C were subsequently determined by enzymatic methods: LDL-C level $=$ TC level - level of cholesterol in the supernatant. The content of LDL-C in the serum samples was expressed as $\mathrm{mg} / 100 \mathrm{ml}$.

Determination of blood glucose. Glucose levels were measured following 12 weeks of feeding. The tails of the rats were stored in a water bath at $45^{\circ} \mathrm{C}$ prior to the collection of blood samples from $1 \mathrm{~mm}$ of the tail end. Glucose detection was conducted according to the ortho-tolidine method (22).

Determination of alanine aminotransferase (ALT), aspartate aminotransferase (AST), non-esterified fatty acid (NEFA), insulin and leptin levels. Serum ALT, AST and NEFA levels were determined according to the manufacturer's instructions (Biosino Bio-Technology And Science Inc.). The insulin concentrations of the serum samples were determined using a Rat Insulin ELISA kit (Mercodia, Uppsala, Sweden), and the tests were $100 \%$ cross-reactive with human and rat insulin. During incubation, insulin in the sample reacted with peroxidase-conjugated anti-insulin and bound to the microtitration well. The unbound enzyme-labeled antibodies were subsequently removed 
<smiles>COc1cc(O)c2c(=O)c3c(OC)c(OC)ccc3oc2c1</smiles>

C<smiles>COc1cc(O)c2c(=O)c3c(O)c(OC)ccc3oc2c1</smiles><smiles>COc1cc(O)c2c(=O)c3c(OC)ccc(OC)c3oc2c1</smiles>

D<smiles>COc1ccc2oc3cc(O)cc(O)c3c(=O)c2c1OC</smiles>

Figure 1. Chemical structures of four flavonoids extracted from Lomatogonium rotatum. (A) 1-hydroxy-3,7,8-trimethoxyxanthone (decussatin); (B) 1-hydroxy-3,5,8-trimethoxyxanthone; (C) methyl swertiamarin; and (D) 6,8-dihydroxy-1,2-dimethoxyxanthone.

by a facile washing step, and the bound conjugate was detected following the addition of 3,3',5,5'-tetra-methylbenzidine. Acids were added to terminate the reaction and the absorbance was measured at $450 \mathrm{~nm}$. Serum leptin levels were determined using a Rat Leptin TiterZyme Enzyme Immunometric Assay kit (Applied Biosystems; Thermo Fisher Scientific, Inc., Foster City, CA, USA), under normal conditions. Leptin was immobilized by a polyclonal antibody on a microtiter plate and, after a short incubation, the excessive sample was rinsed, and leptin polyclonal antibody labeled with horseradish peroxidase was added. Subsequently, the excessive antibody was rinsed and the substrate was added prior to incubation for $30 \mathrm{~min}$. The absorbance of the resultant colored solutions was detected at $450 \mathrm{~nm}$, which was directly proportional to the concentrations of leptin in the respective samples (23).

Determination of total lipids, TG and TC in the liver. To detect the levels of hepatic total lipids, TG and TC, the rat livers were homogenized using a mixed chloroform/methanol/water (8:4:3) solution (LabGEN 7 Homogenizer; Cole-Parmer, Vernon Hills, IL, USA). The resultant mixture was shaken at $37^{\circ} \mathrm{C}$ for $1 \mathrm{~h}$ and centrifuged at 2,000 x g for $10 \mathrm{~min}$. Subsequently, the bottom layer was collected and resuspended in order to analyze the hepatic lipids. The levels of TG, TC and total lipids were measured according to the enzymatic protocol outlined by Biosino Bio-Technology And Science Inc. (24).

Reverse transcription polymerase chain reaction (RT-PCR) analysis. Total RNA was isolated from liver tissue samples using ISOGEN ${ }^{\circledR}$ reagent (Nippon Gene Co., Ltd., Toyama, Japan). Briefly, cDNA was prepared from $5 \mu \mathrm{g}$ total RNA, oligo (dT)18 primer and Moloney murine leukemia virus reverse transcriptase (Promega Biotech Co., Ltd., Beijing, China) by incubation at $40^{\circ} \mathrm{C}$ for $90 \mathrm{~min}$. The total PCR volume was $50 \mu \mathrm{l}$ containing dNTPs, $1 \mu \mathrm{l}$ reaction buffer, $1 \mu \mathrm{M}$ primers (FAS, forward 5'-CCACTAGAAGCGTCTGCT GATCTG-3'; reverse, 5'-TGCTATGTCCTACATATCGAG GACGC-3'), $2 \mu 1$ reverse transcriptase and 50 Uml-1 Taq DNA polymerase. A total of $5 \mu \mathrm{l}$ PCR products were subsequently separated by $2 \%$ agarose gel electrophoresis and were visualized via staining with ethidium bromide.
Western blotting. Each liver sample was homogenized in lysis buffer containing $50 \mathrm{mM}$ Tris- $\mathrm{HCl}$ buffer, $50 \mathrm{mM} \mathrm{NaF}, 5 \mathrm{mM}$ sodium pyrophosphate, $0.25 \mathrm{M}$ sucrose, $1 \mathrm{mM}$ ethylenediaminetetraacetic acid, $1 \mathrm{mM}$ ethylenediaminetetraacetic acid, $1 \mathrm{mM}$ dithiothreitol, $0.1 \mathrm{mM}$ phenylmethylsulfonyl fluoride and $0.5 \%$ sodium dodecyl sulfate $(\mathrm{pH} 7.5)$. The tissue lysates were then centrifuged in order to remove insoluble substances and the respective protein contents were measured using a Bio-Rad Protein Assay kit (Bio-Rad Laboratories, Inc., Hercules, CA, USA). The proteins were subsequently separated by $10 \%$ SDS-PAGE (Bio-Rad Laboratories, Inc.) and electro-transferred onto a polyvinylidene difluoride membrane, which was then pre-incubated overnight at $4^{\circ} \mathrm{C}$ in phosphate-buffered saline containing $0.01 \%$ Tween-20, $1 \%$ bovine serum albumin (Nanjing SenBeiJia Biological Technology Co., Ltd., Nanjing, China) and $0.2 \% \mathrm{NaN}_{3}$. Following this, the proteins were successively incubated with various primary antibodies and secondary anti-rabbit/goat/mouse IgG conjugated to horseradish peroxidase. The immunoreactive bands were visualized using enhanced chemiluminescent reagents.

Statistical analysis. All data were analyzed using SPSS 16.0 software (SPSS Inc., Chicago, IL, USA) and expressed as the mean \pm standard deviation. The mean values were derived from three independent experiments. Two groups were compared by Student's t-test (Mann-Whitney test was used in the case of heterogeneity of variance), and multiple groups were compared by one-way analysis of variance with StudentNewman-Keuls post-hoc analysis. $\mathrm{P}<0.05$ was considered to indicate a statistically significant difference.

\section{Results}

Effects of flavonoids extracted from L. rotatum on body weight and diet intake. The metabolism of Wistar rats may be affected by $60 \%$ fructose intake, which is associated with as glucose tolerance, high serum TG levels and increased insulin resistance; therefore, rats in the model group were fed foodstuff containing $60 \%$ fructose $(25,26)$. The present study aimed to compare the effects of various flavonoids from L. rotatum on 6-week-old Wistar rats with high fruc- 
Table I. Effects of flavonoids extracted from Lomatogonium rotatum on the weight of liver, kidney and adipose tissues.

\begin{tabular}{|c|c|c|c|c|c|c|}
\hline \multirow[b]{2}{*}{ Group } & \multicolumn{2}{|c|}{ Liver } & \multicolumn{2}{|c|}{ Epididymal adipose tissue } & \multicolumn{2}{|c|}{ Kidney } \\
\hline & Weight (g) & Relative weight & Weight (g) & Relative weight & Weight (g) & Relative weight \\
\hline Control & $15.8 \pm 2.2$ & $3.6 \pm 0.3$ & $7.2 \pm 0.3$ & $1.5 \pm 0.2^{\mathrm{a}}$ & $3.3 \pm 0.2$ & $0.77 \pm 0.2$ \\
\hline Model & $16.5 \pm 0.9$ & $3.8 \pm 0.4$ & $6.8 \pm 0.5$ & $1.7 \pm 0.4^{\mathrm{a}}$ & $3.1 \pm 0.5$ & $0.82 \pm 0.3^{\mathrm{a}}$ \\
\hline A & $14.9 \pm 2.4$ & $4.1 \pm 0.5$ & $5.0 \pm 1.1$ & $1.3 \pm 0.4^{\mathrm{b}}$ & $2.7 \pm 0.3$ & $0.74 \pm 0.4^{\mathrm{b}}$ \\
\hline B & $13.8 \pm 1.5$ & $4.3 \pm 0.3^{b}$ & $5.2 \pm 0.4$ & $1.3 \pm 0.5^{\mathrm{b}}$ & $2.5 \pm 0.1^{\mathrm{b}}$ & $0.77 \pm 0.3$ \\
\hline $\mathrm{C}$ & $14.7 \pm 1.5$ & $4.1 \pm 0.2$ & $4.9 \pm 1.0^{\mathrm{b}}$ & $1.4 \pm 0.2^{\mathrm{b}}$ & $2.5 \pm 0.4^{\mathrm{b}}$ & $0.71 \pm 0.1^{\mathrm{b}}$ \\
\hline $\mathrm{D}$ & $14.2 \pm 2.3$ & $4.2 \pm 0.4$ & $4.7 \pm 0.6^{\mathrm{b}}$ & $1.4 \pm 0.3^{\mathrm{b}}$ & $2.6 \pm 0.2$ & $0.72 \pm 0.2^{\mathrm{b}}$ \\
\hline
\end{tabular}

${ }^{\mathrm{a}} \mathrm{P}<0.05$ vs. the control group; ${ }^{\mathrm{b}} \mathrm{P}<0.05$ vs. the model group. A-D, flavonoid A-D groups.

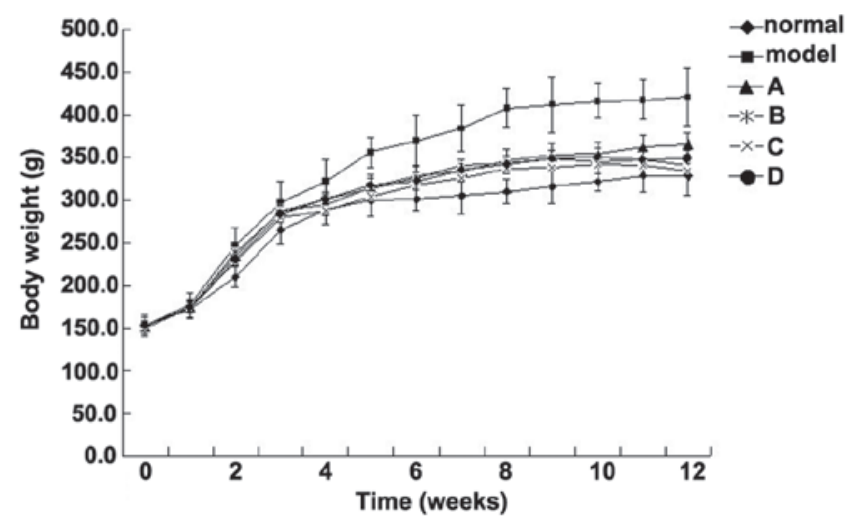

Figure 2. Changes in the body weight of rats fed $60 \%$ fructose and $5 \mathrm{mg} / \mathrm{kg}$ flavonoids for 12 weeks. Data are presented as the mean \pm standard deviation. •Control group; ${ }^{\bullet}$ model group; ${ }^{\mathbf{A}}$ Group A; "Group B; ${ }^{\times}$Group C; ${ }^{\bullet}$ Group D.

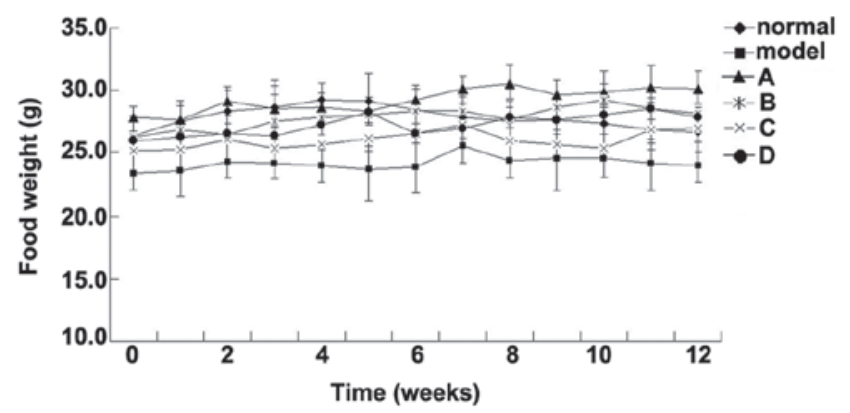

Figure 3. Daily food intake data of the various groups. ${ }^{\star}$ Control, $26.5 \pm 1.2 \mathrm{~g}$; -model, $23.9 \pm 2.9 \mathrm{~g} ;{ }^{\star}$ flavonoid A, $27.7 \pm 1.7 \mathrm{~g} ;{ }^{*}$ flavonoid B, $26.2 \pm 2.2 \mathrm{~g} ;{ }^{\times}$flavonoid C: $25.1 \pm 1.2 \mathrm{~g}$; and $\bullet$ flavonoid D groups: $26.8 \pm 1.4 \mathrm{~g}$.

tose-induced hyperlipidemia. Experimental rats, weighing $\sim 150$ g each, were divided into six groups $(n=10)$, and fed various diets for 12 weeks. The rats were weighed weekly and the observed weight changes are outlined in Fig. 2. The body weight of the rats in the model group was significantly increased from the 3rd week, whereas the weight of the rats in the control and flavonoid groups increased steadily without significant differences. The flavonoid D group exhibited the lowest mean weight. The food intake data for all of the experimental groups are presented in Fig. 3. Food

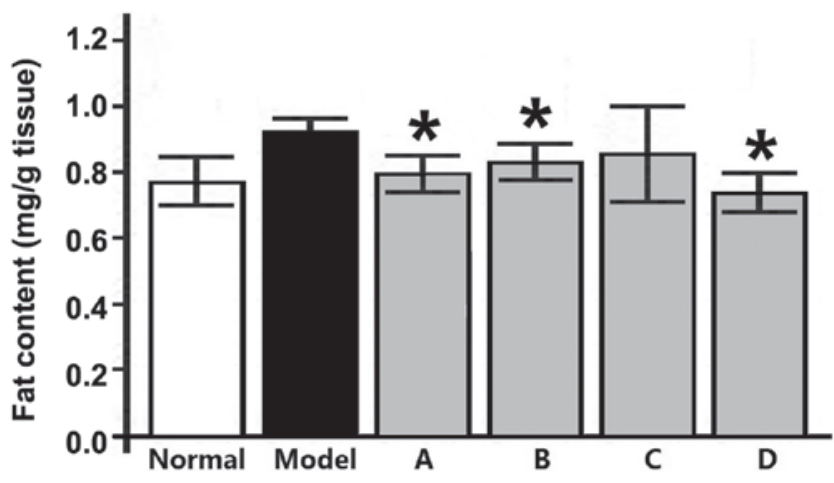

Figure 4. Effects of flavonoids extracted from Lomatogonium rotatum on hepatic fat accumulation in rats fed a fructose-rich diet. Data are presented as the mean \pm standard deviation $(n=10)$. ${ }^{*} \mathrm{P}<0.05$ vs. the model group. A-D, flavonoid A-D groups.

intake volume and body weight were linearly correlated in all groups except the model group.

Effects of flavonoids extracted from L. rotatum on liver, kidney and adipose tissue weight. The weight of the rat hepatic, renal and epididymal adipose tissues are outlined in Table I. L. rotatum flavonoids did not influence the liver weight of the rats; whereas the epididymal adipose tissues of the rats fed various flavonoids weighed less, as compared with those only fed fructose. In addition, the weight of the kidney tissues harvested from rats fed L. rotatum flavonoids were also lower, as compared with the model group, with the exception of the flavonoid B group.

Effects of flavonoids extracted from L. rotatum on lipid metabolism. It has been revealed that rats fed a high-fructose diet may suffer from increased insulin resistance, hyperinsulinemia, hypertriglyceridemia and hypertension. To verify the effects of $L$. rotatum flavonoids on lipid metabolism, serum and liver tissue samples from Wistar rats were analyzed. In the present study, a high-fructose diet significantly elevated the levels of serum insulin, leptin and NEFA (Table II). Following a 12 -week administration of L rotatum flavonoids, the levels of fasting blood glucose, feeding blood glucose and leptin in the serum had decreased to normal. In addition, the 
Table II. Relative clinical and biochemical indices following a 12-week administration.

\begin{tabular}{|c|c|c|c|c|c|c|c|}
\hline Group & $\begin{array}{l}\text { ALT } \\
\left(\mathrm{U} \cdot \cdot^{-1}\right)\end{array}$ & $\begin{array}{l}\text { AST } \\
\left(\mathrm{U} \cdot 1^{-1}\right)\end{array}$ & 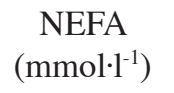 & $\begin{array}{c}\text { Fasting blood } \\
\text { glucose }\left(\mathrm{mg} \cdot \mathrm{dl}^{-1}\right)\end{array}$ & 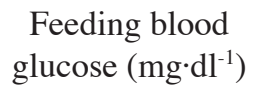 & $\begin{array}{l}\text { Insulin } \\
\left(\mathrm{pmol}^{-1} \mathrm{-}^{-1}\right)\end{array}$ & $\begin{array}{l}\text { Leptin } \\
\left(\operatorname{ngm} \cdot l^{-1}\right)\end{array}$ \\
\hline Control & $31.5 \pm 0.26$ & $105.3 \pm 1.41$ & $0.17 \pm 0.02$ & $63.2 \pm 4.7$ & $95.6 \pm 10.1$ & $142.6 \pm 36.5$ & $20.04 \pm 1.2$ \\
\hline Model & $26.3 \pm 0.34^{\mathrm{a}}$ & $95.4 \pm 0.97^{\mathrm{a}}$ & $0.33 \pm 0.01^{\mathrm{a}}$ & $73.5 \pm 3.6^{\mathrm{a}}$ & $122.6 \pm 20.3^{a}$ & $188.7 \pm 42.2^{\mathrm{a}}$ & $25.4 \pm 2.2^{\mathrm{a}}$ \\
\hline A & $23.7 \pm 0.65^{\mathrm{b}}$ & $99.8 \pm 0.45^{\mathrm{b}}$ & $0.23 \pm 0.05^{\mathrm{b}}$ & $59.6 \pm 3.5^{\mathrm{b}}$ & $92.6 \pm 16.8^{b}$ & $109.6 \pm 33.1^{\mathrm{b}}$ & $19.6 \pm 2.5^{\mathrm{b}}$ \\
\hline B & $25.2 \pm 0.42$ & $92.4 \pm 0.87$ & $0.26 \pm 0.03$ & $60.1 \pm 4.5^{\mathrm{b}}$ & $95.8 \pm 17.6^{\mathrm{b}}$ & $121.4 \pm 35.6^{\mathrm{b}}$ & $22.3 \pm 0.8^{b}$ \\
\hline $\mathrm{C}$ & $24.1 \pm 0.24^{\mathrm{b}}$ & $99.3 \pm 0.64^{b}$ & $0.24 \pm 0.01^{\mathrm{b}}$ & $64.5 \pm 1.2^{\mathrm{b}}$ & $101.3 \pm 15.4$ & $133.4 \pm 45.6^{\mathrm{b}}$ & $20.4 \pm 1.5^{\mathrm{b}}$ \\
\hline $\mathrm{D}$ & $22.8 \pm 0.76^{\mathrm{b}}$ & $91.5 \pm 0.75$ & $0.24 \pm 0.05^{\mathrm{b}}$ & $63.3 \pm 6.0^{\mathrm{b}}$ & $97.8 \pm 11.9^{b}$ & $136.8 \pm 26.1^{\mathrm{b}}$ & $21.8 \pm 3.3^{\mathrm{b}}$ \\
\hline
\end{tabular}

${ }^{\mathrm{a}} \mathrm{P}<0.05$ vs the control group; ${ }^{\mathrm{b}} \mathrm{P}<0.05$ vs the model group. A-D, flavonoid A-D groups. ALT, alanine transaminase; AST, aspartate transaminase; NEFA, non-esterified fatty acids.

A
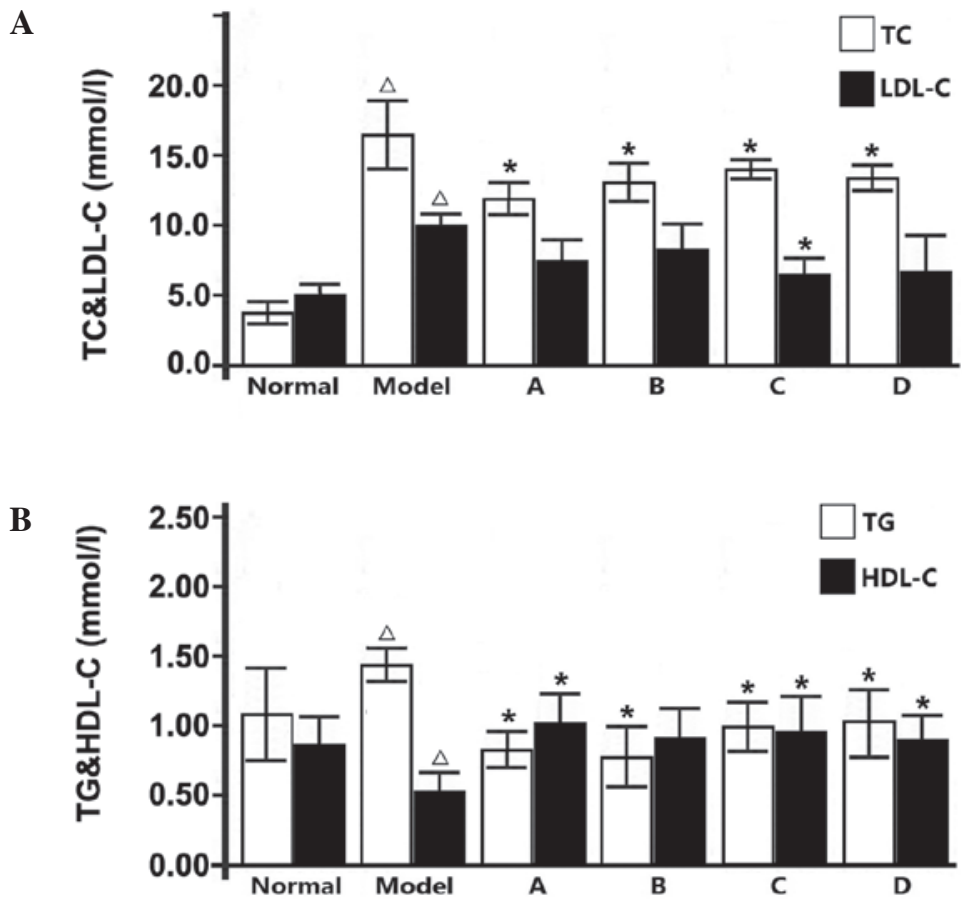

Figure 5. Effects of flavonoids extracted from Lomatogonium rotatum on blood lipid indices. (A) TC (white) and LDL-C (black); (B) TG (white) and HDL-C (black). ${ }^{\Delta} \mathrm{P}<0.05$ vs. the control group; ${ }^{*} \mathrm{P}<0.05$ vs. the model group. Data are presented as the mean \pm standard deviation ( $\left.\mathrm{n}=10\right)$. TC, total cholesterol; LDL-C, low-density lipoprotein-cholesterol; HDL-C, high-density lipoprotein-cholesterol. A-D, flavonoid A-D groups.

rats in flavonoid groups $\mathrm{A}$ and $\mathrm{D}$ exhibited reduced levels of serum cholesterol, insulin, leptin and NEFA (Table II). Rats in flavonoid B group demonstrated improved liver function; however, function was not completely recovered. In addition, in the flavonoid $\mathrm{C}$ group feeding blood glucose levels did not return to normal.

To determine the effects of $L$. rotatum flavonoids on the homeostasis of liver fat, hepatic fat accumulation was investigated in rats. The resultant liver fat content (Fig. 4) and TG and cholesterol levels (Fig. 5) indicate that fructose-rich foods may significantly increase fat accumulation in the liver. The fat content, and serum TG and cholesterol levels were all significantly lowered after 12 -week administration of L rotatum flavonoids, as compared with rats fed only a high-fructose diet. Thus suggesting that $L$. rotatum flavonoids successfully reduced hepatic fat content, and blood TG and cholesterol levels, as well as increasing serum HDL-C levels. As outlined in Fig.5, flavonoid A demonstrated good therapeutic action in reducing total cholesterol; however, the LDL-C levels were not significantly altered. Furthermore, following flavonoid C administration the resultant serum lipid parameters demonstrated good pharmacological activity, with a significant reduction in LDL-C levels $(\mathrm{P}<0.05)$, and flavonoids B and D functioned similarly.

Effects of flavonoids extracted from L. rotatum on the expression levels of FAS and $p A M P K$. Previous studies have demonstrated that fructose-rich foods may elevate TG levels in the liver and blood, and a high fructose intake may result in hypertriglyceridemia in rats. Fructose-induced hypertriglyceridemia is considered to originate from the excessive secretion of TG in the liver (27), with the enhanced expression of several 
A

\section{FAS}
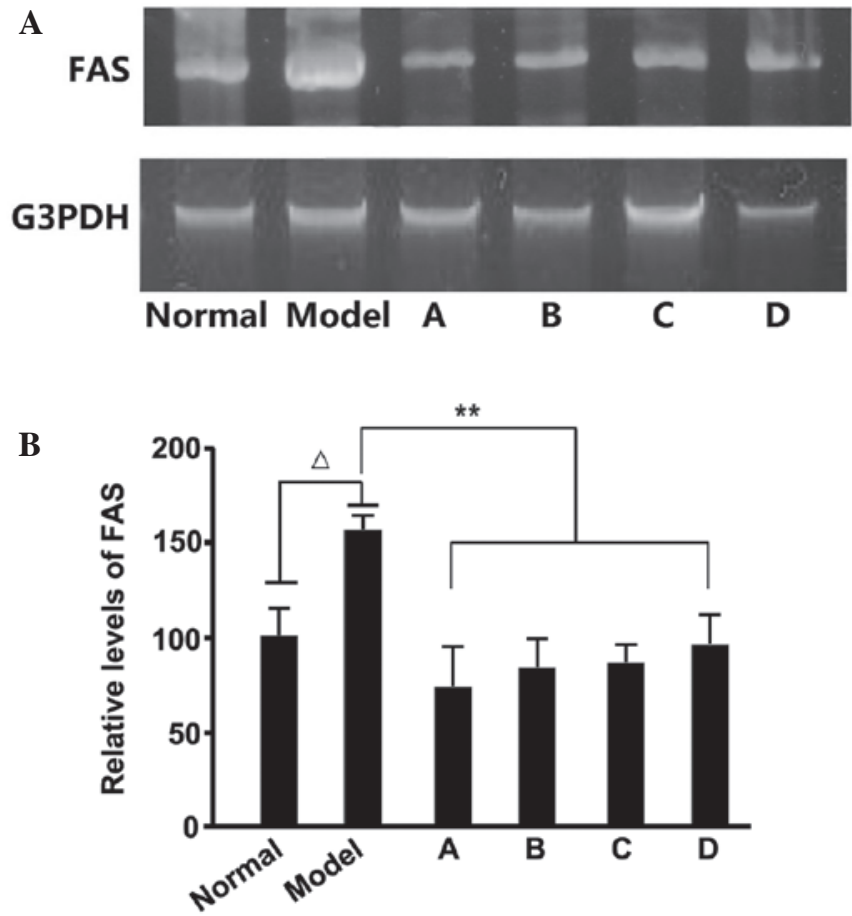

Figure 6. FAS mRNA expression levels, as detected by reverse transcription polymerase chain reaction. (A) Agarose gel electrophoresis analysis and (B) relative FAS mRNA expression levels. ${ }^{{ }} \mathrm{P}<0.05$ vs. the control; ${ }^{* *} \mathrm{P}<0.01$ vs. the model group. FAS, fatty acid synthase; A-D, flavonoid A-D groups.

enzymes, including FAS, associated with the promotion of hepatic TG secretion. After detecting the FAS levels in rat liver samples, we hypothesize that the hypolipidemic effects of L. rotatum flavonoids are realized by inhibiting the expression of FAS. We also estimate that FAS activity is controlled by enzyme content rather than changes in chemical bond or enzymatic structure. RNA and protein samples were extracted from the liver of rats fed various $L$. rotatum flavonoids, in order to conduct RT-PCR and western blotting. In the present study, the administration of a high-fructose diet significantly increased FAS mRNA and protein expression levels (Figs. 6 and 7) in rats, as compared with the other groups. FAS mRNA expression levels were significantly decreased $(\mathrm{P}<0.01)$ in the rats fed $L$. rotatum flavonoids, and the four flavonoids appeared to function identically. In addition, the protein levels of FAS were successfully controlled in all of the flavonoid groups; however, the effects of flavonoid $\mathrm{D}$ were most evident $(\mathrm{P}<0.01)$. Another important indicator is the phosphorylation of AMPK in the liver of the rats. Western blot analysis demonstrated that flavonoid $\mathrm{C}$ significantly decreased the threonine-172 phosphorylation of AMPK in the liver lysates ( $\mathrm{P}<0.01$; Fig. 7).

\section{Discussion}

Hypercholesterolemia and hypertriglyceridemia are considered important factors associated with the incidence of atherosclerosis and CHD. In the present study, rats fed a high-fructose diet demonstrated hyperlipidemia, increased body weight, adipose tissue and blood insulin levels, and decreased glucose tolerance. A previous study demonstrated that Wistar rats experienced a significant increase in lipid levels after being

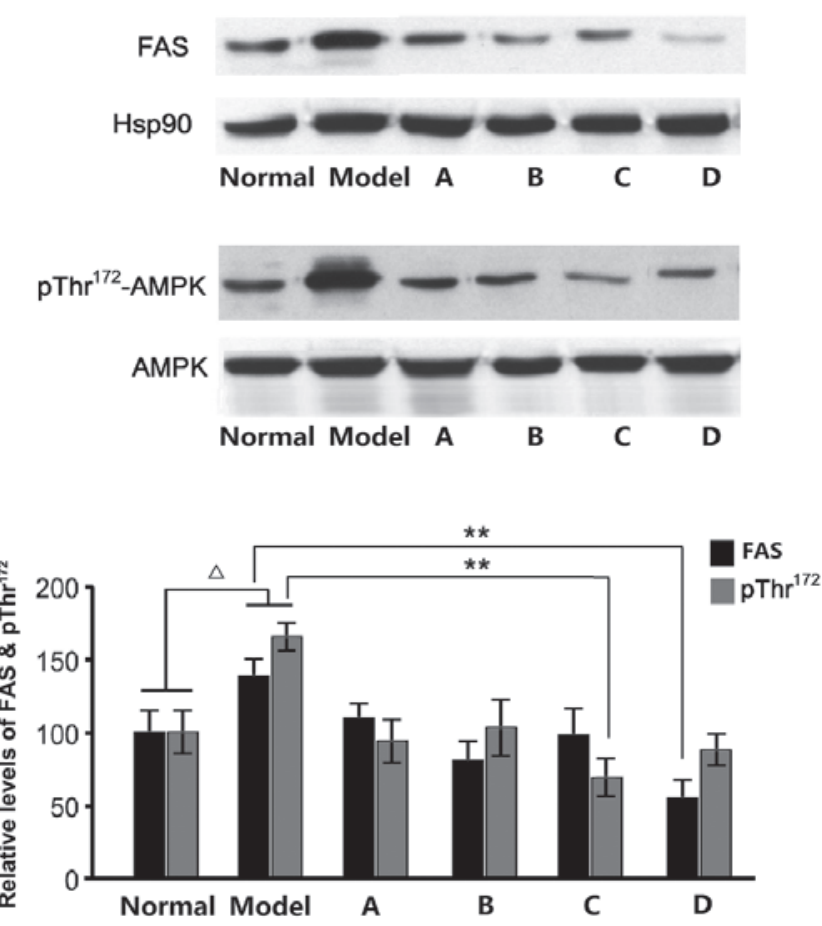

Figure 7. Protein expression levels of FAS, and $\mathrm{pThr}^{172}$-AMPK in the liver. ${ }^{\Delta} \mathrm{P}<0.05$ vs. the control group; ${ }^{* *} \mathrm{P}<0.01$. Black, FAS; grey, $\mathrm{pThr}{ }^{172}-\mathrm{AMPK}$. Hsp90, heat shock protein 90; FAS, fatty acid synthase; pThr $^{172}$-AMPK, threonine-172 phosphorylated adenosine monophosphate-activated protein kinase; A-D, flavonoid A-D groups.

fed a high-fructose diet for two weeks, and the effect became more apparent after 10 weeks (28). Flavonoid A, which is the most frequently assessed of the four flavonoids, is capable of preventing atherosclerosis by decreasing blood pressure. Flavonoids A-D are obtained from the same plant and have similar structures; therefore, their common effects should be considered $(9,29)$. In the present study, the levels of TC, LDL-C and TG were significantly increased, and the HDL-C levels were significantly decreased in the model group, as compared with the control group, suggesting that the model was successfully established. In the flavonoid $\mathrm{C}$ group, the four serum lipid parameters were improved following treatment, and LDL-C was the only parameter to not demonstrate a significant change in the flavonoid D group. Furthermore, TC, TG and HDL-C levels were significantly improved in the flavonoid A group, and TC and TG were significantly decreased in the flavonoid B group.

Following a 12-week administration of L. rotatum flavonoids, serum levels of fasting blood glucose and feeding blood glucose were significantly decreased. The rats in the flavonoid $\mathrm{A}$ and $\mathrm{D}$ groups demonstrated reduced levels of serum insulin; however, feeding blood glucose levels did not return to normal in the flavonoid $\mathrm{C}$ group. These results suggested that flavonoid $\mathrm{C}$ may produce insulin resistance in rats, which should be the focus of more detailed studies in the future (30). Leptin is encoded by the $\mathrm{Ob}$ gene, and the amount of adipose tissue and insulin secretion can increase the levels of serum leptin. Therefore, the leptin levels of rats fed a high-fructose diet should be higher, as compared with those in the control group. The present study demonstrated that high-fructose foods may lead to excessive insulin secretion, thereby stimulating the 
production of leptin $(29,31)$. All L. rotatum flavonoids were able to downregulate leptin and, owing to their potential hypolipidemic effects, further studies investigating the flavonoids of various Mongolian medicines are recommended in the future.

Epidemiological studies have demonstrated that flavonoid intake is inversely related to CHD. FAS is involved in energy metabolism, and is associated with various human diseases, including obesity, cardiovascular disease and cancer. Previous studies have reported that epigallocatechin 3-gallate (EGCG) in flavonoids may inhibit FAS in the liver of broiler chickens $(32,33)$. In the present study, the majority of the flavonoids successfully reduced the relative weight of epididymal adipose tissue. Therefore, the authors of the present study infer that flavonoids A, B and D have a similar effect to EGCG in inhibiting the activity of FAS. A previous in-depth study investigated the molecular dynamic mechanisms of L. rotatum flavonoids on the expression of FAS (6), and such studies should be continued in the future. All L. rotatum flavonoids may inhibit the expression of FAS in the liver by stimulating AMPK activity in hepatocyte cells via the liver kinase B1 pathway (34). Furthermore, the majority of flavonoids decreased the threonine-172 phosphorylation of AMPK in the liver lysate, which suggested that flavonoids stimulate AMPK activity, thereby reducing fatty acid synthesis in the liver and fat accumulation (35). Furthermore, the activities of acetyl-CoA carboxylase and FAS may be inhibited; however, the mechanisms of FAS inhibition and anti-obesity remain unclear, and future studies are required.

In conclusion, the present study demonstrated that certain flavonoids extracted from $L$. rotatum may mitigate hypercholesterolemia and hypertriglyceridemia induced by the intake of high-fructose foods, as well as improve the metabolism of lipids and leptin in rats with insulin resistance. The four flavonoids that were investigated decreased the levels of TG, total cholesterol, leptin and insulin within a certain range, and improved insulin resistance, liver function, and HDL-C levels. The present study also demonstrated that flavonoid $\mathrm{C}$ exhibited the best overall effects and inhibited FAS in the liver tissue of rats. However, the metabolic mechanisms investigated in the present study are not identical between humans and experimental rats, therefore it remains unclear whether the flavonoids may also prevent fat accumulation in the human liver. As such, the pharmacological effects of flavonoids should be further investigated in humans. These findings may contribute to the treatment of fatty liver and obesity-associated diseases in humans.

\section{Acknowledgements}

The present study was financially supported by the Nature Science Foundation of Inner Mongolia Autonomous Region (grant no. 2013MS1224), the Scientific Project of the Affiliated Hospital of Inner Mongolia Medical University (grant no. NYFY2010YB006), the Inner Mongolia Medical University Youth Innovation Fund (grant no. NY2010QN002), and the Key Scientific Fund of the Affiliated Hospital of Inner Mongolia Medical University (grant no. NYFYZD20130158).

\section{References}

1. Li YL, Suo YR, Liao ZX and Ding LS: The glycosides from Lomatogonium rotatum. Nat Prod Res 22: 198-202, 2008.
2. Zhao N, Wang M and Li XE: Biological macro-idea and criterion of osteopathic fracture immobilization in China's traditional Mongolian medicine. J Tradit Chin Med 32: 114-118, 2012.

3. Burie: Preliminary study on classification and nomenclative system of Mongolian traditional medicine. Zhong Guo Zhong Yao Za Zhi 36: 1539-1541, 2011 (In Chinese).

4. Li ZH, Zhang AH, Yun XH, Zhang CH, Zhu SD, Zou DZ, Bi YQ and Li MH: Ecology suitability study of Lomatogonium rotatum in Inner Mongolia. Zhong Guo Zhong Yao Za Zhi 40: 778-784, 2015 (In Chinese).

5. Schultz A, Barbosa-da-Silva S, Aguila MB and Mandarim-de-Lacerda CA: Differences and similarities in hepatic lipogenesis, gluconeogenesis and oxidative imbalance in mice fed diets rich in fructose or sucrose. Food Funct 6: 1684-1691, 2015.

6. Huang HC and Lin JK: Pu-erh tea, green tea, and black tea suppresses hyperlipidemia, hyperleptinemia and fatty acid synthase through activating AMPK in rats fed a high-fructose diet. Food Funct 3: 170-177, 2012.

7. Hada DS, Garg S, Ramteke GB and Ratre MS: Effect of Nonsurgical Periodontal Treatment on Clinical and Biochemical Risk Markers of Cardiovascular Disease: A Randomized Trial. J Periodontol 86: 1-16, 2015.

8. Pant N, Jain DC and Bhakuni RS: Some chemical constituents of Swertia chirata. Indian J Chem B 41: 1980-1986, 2002.

9. Jia J, Chen T, Wang P, Chen G, You J, Liu Y and Li Y: Preparative separation of methylswertianin, swerchirin and decussatin from the Tibetan medicinal plant Swertia mussotii using high-speed counter-current chromatography. Phytochem Anal 23: 332-336, 2012.

10. Chakravarty AK, Mukhopadhyay S, Moitra SK and Das B: Syringaresinol, a hepatoprotective agent and other constituents from Swertia chirata. India J Chem B 33: 405-408, 1994.

11. Wang J, Liu Y, Cai Y, Zhang F, Xia G and Xiang F: Cloning and functional analysis of geraniol 10-hydroxylase, a cytochrome P450 from Swertia mussotii Franch. Biosci Biotechnol Biochem 74: 1583-1590, 2010.

12. Chiba K, Yamazaki M,Kikuchi M, Kakuda R and and Kikuchi M: New physiological function of secoiridoids: Neuritogenic activity in PC12h cells. J Nat Med 65: 186-190, 2011.

13. Lv Y, Zhang HT, Wang YF, Zhu H, Long P, Wang ZW, Zhang N and Zhang $\mathrm{CH}$ : Preliminary comparative study of swertiamarin and swertisin on three kinds of Digeda-species Mongolian medicinal materials. Zhong Guo Zhong Yao Za Zhi 40: 804-806, 2015 (In Chinese).

14. Marques MB,Ribeiro-Oliveira A Jr, Guimarães J, Nascimento GF, Anjos AP, Vilas-Boas WW, Santos RA, Thomas JD, Igreja SM, Grossman AB, et al: Modifications in basal and stress-induced hypothalamic AMP-activated protein kinase (AMPK) activity in rats chronically treated with an angiotensin II receptor blocker. Stress 15: 554-561, 2012.

15. Alaribe CS, Shode F, Coker HA, Ayoola G, Sunday A, Singh N and Iwuanyanwu S: Antimicrobial activities of hexane extract and decussatin from stembark extract of Ficus congensis. Int J Mol Sci 12: 2750-2756, 2011.

16. Reddy SS, Ramatholisamma P, Karuna R and Saralakumari D: Preventive effect of Tinospora cordifolia against high-fructose diet-induced insulin resistance and oxidative stress in male Wistar rats. Food Chem Toxicol 47: 2224-2229, 2009.

17. Uluışı D and Keskin E: Effects of ginseng and echinacea on cytokine mRNA expression in rats. ScientificWorldJournal 2012: 942025, 2012.

18. Moura LP, Figueredo GA, Bertolini NO, Ceccato M, Pereira JR, Sponton AC and de Mello MA: Dietary restriction, caloric value and the accumulation of hepatic fat. Lipids Health Dis 11: 2012.

19. Li Y, Yang H, Han WW, Liao MX and Lu YQ: An enzyme sensor for phenolic compounds analysis. Guang Pu Xue Yu Guang Pu Fen Xi 30: 571-574, 2010 (In Chinese).

20. Araújo AN, Lima JL, Pinto PC and Saraiva ML: Enzymatic determination of glucose in milk samples by sequential injection analysis. Anal Sci 25: 687-692, 2009.

21. Shahzad F, Tawwab S and Ahsan U: Lipid profiles of non-diabetic healthy and ischaemic heart disease patients. J Coll Physicians Surg Pak 23: 242-246, 2013.

22. Leguit P Jr: Compartment syndrome of the upper arm. Neth J Surg 34: 123-126, 1982.

23. Wang X, Li S and Zhou Z: A rapid one-step method of EIA for detection of circulating antigen of Schistosoma japonicum. Chin Med J (Engl) 112: 124-128, 1999. 
24. Diraison F, Pachiaudi C and Beylot M: In vivo measurement of plasma cholesterol and fatty acid synthesis with deuterated water: Determination of the average number of deuterium atoms incorporated. Metabolism 45: 817-821, 1996.

25. Reddy SS, Ramatholisamma P, Ramesh B, Baskar R and Saralakumari D: Beneficiary effect of Tinospora cordifolia against high-fructose diet induced abnormalities in carbohydrate and lipid metabolism in Wistar rats. Horm Metab Res 41: 741-746, 2009.

26. Barbosa CR, Albuquerque EM, Faria EC, Oliveira HC and Castilho LN: Opposite lipemic response of Wistar rats and C57BL/6 mice to dietary glucose or fructose supplementation. Braz J Med Biol Res 40: 323-331, 2007.

27. Shrestha S, Ehlers SJ, Lee JY, Fernandez ML and Koo SI: Dietary green tea extract lowers plasma and hepatic triglycerides and decreases the expression of sterol regulatory element-binding protein-1c mRNA and its responsive genes in fructose-fed, ovariectomized rats. J Nutr 139: 640-645, 2009.

28. Collino M, Aragno M, Castiglia S, Miglio G, Tomasinelli C, Boccuzzi G, Thiemermann C and Fantozzi R: Pioglitazone improves lipid and insulin levels in overweight rats on a high cholesterol and fructose diet by decreasing hepatic inflammation. Br J Pharmacol 160: 1892-1902, 2010.

29. Chintalwar GJ and Chattopadhyay S: Structural confirmation of decussatin, a Swertia decussata xanthone. Nat Prod Res 20 : 53-56, 2006.
30. Frangioudakis G, Gyte AC, Loxham SJ and Poucher SM: The intravenous glucose tolerance test in cannulated Wistar rats: A robust method for the in vivo assessment of glucose-stimulated insulin secretion. J Pharmacol Toxicol Methods 57: 106-113, 2008.

31. Zhang X, Zhao Y, Zhang M, Pang X, Xu J, Kang C, Li M, Zhang C, Zhang Z, Zhang Y, et al: Structural changes of gut microbiota during berberine-mediated prevention of obesity and insulin resistance in high-fat diet-fed rats. PLoS One 7: e42529, 2012.

32. Zhao YX, Liang WJ, Fan HJ, Ma QY, Tian WX, Dai HF, Jiang HZ, $\mathrm{Li}$ N and Ma XF: Fatty acid synthase inhibitors from the hulls of Nephelium lappaceum L. Carbohydr Res 346: 1302-1306, 2011.

33. Kim GS, Park HJ, Woo JH, Kim MK, Koh PO, Min W, Ko YG, Kim CH, Won CK and Cho JH: Citrus aurantium flavonoids inhibit adipogenesis through the Akt signaling pathway in 3T3-L1 cells. BMC Complement Altern Med 12: 31, 2012.

34. Pil Hwang Y, Gyun Kim H, Choi JH, Truong Do M, Tran TP, Chun HK, Chung YC, Jeong TC and Jeong HG: 3-Caffeoyl, 4-dihydrocaffeoylquinic acid from Salicornia herbacea attenuates high glucose-induced hepatic lipogenesis in human HepG2 cells through activation of the liver kinase B1 and silent information regulator T1/ AMPK-dependent pathway. Mol Nutr Food Res 57: 471-482, 2013.

35. Do MT, Kim HG, Choi JH, Khanal T, Park BH, Tran TP, Hwang YP, Na M and Jeong HG: Phillyrin attenuates high glucose-induced lipid accumulation in human HepG2 hepatocytes through the activation of LKB1/AMP-activated protein kinase-dependent signalling. Food Chem 136: 415-425, 2013. 